\title{
Key strategic issues pharmaceutical industry of SCM: A systematic literature review
}

\author{
Erick Fernando, Meyliana, Harco Leslie Hendric Spits Warnars, Edi Abdurachman \\ Information Systems Department, School of Information Systems, Bina Nusantara University, Jakarta, Indonesia
}

\section{Article Info}

Article history:

Received Jul 12, 2018

Revised Dec 1, 2018

Accepted Sep 26, 2019

\section{Keywords:}

Key strategic issues

Pharmaceutical industry

Supply chain management

Systematic literature review

\begin{abstract}
In this global era, making competition in the pharmaceutical industry is very treacly. Implementation Supply chain management is the process of planning and managing all sourcing, procurement, distribution activities to increase value to customers and interested companies. Pharmaceutical companies are one that has a very complex supply chain. This article will discuss the main issues that can improve the industry strategically. This research is done by the systematic approach of literature to find things related to research. This study used 64 articles from search results. The results of this search are key issues in the pharmaceutical industry such as product and process development, capacity planning, factory, and network design, e-business and IT applications, inventory management, outsourcing and reverse logistics, lean manufacturing, performance measures, people, and information technology. All of these findings are issues that improve the performance of supply chain management in the pharmaceutical industry.
\end{abstract}

This is an open access article under the CC BY-SA license.

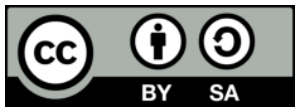

\section{Corresponding Author:}

Erick Fernando,

Information Systems Department, School of Information Systems,

Bina Nusantara University, Jakarta, Indonesia.

Email: erick.fernando_88@yahoo.com

\section{INTRODUCTION}

Supply chain management is the process of planning and managing all sourcing, procurement, distribution activities to increase value to customers and interested companies [1,2]. Pharmaceutical companies are one that has a very complex supply chain. However, in recent decades, important supply chain decisions, such as those related to the acquisition or introduction of new products [3], operating processes and organizations that have contributed to the discovery, development, and manufacture of drugs so as to be more useful to life human $[1,4]$. The benefits of drugs are not separated from the role of all processes that exist in the pharmaceutical industry, and then it requires a supply chain [5]. According to Ying Xie and Breen [5], the pharmaceutical supply chain is a special supply chain from another where the drug process takes placemaking, delivering, and until consumed by the customer. With so much importance the supply chain management approach makes the company's success in competing [6-8]. Lee [9] argues that supply chain management is a complicated, complete, and challenging thing in its implementation. This is due to an ever-changing trend in expanding a wide range of products, non-short life cycle processes, ever-increasing outsourcing, rapid technological developments, and business globalization.

Existing challenges have an impact on high cost and time spent in testing in the process of drug discovery and development. This process is even in line with the high uncertainty of demand and the required production capacity planning process [10]. This has led to the slow growth and substantial decline in the development of new drugs in the pharmaceutical industry, thus making the main Challenge [11, 12]. According to the WHO [13], the Impact caused drug prices to rise to as high as 650 percent of the prevailing 
international standards in developing and advanced countries. In addition, the unavailability of inexpensive drugs in the market $[11,14]$, the current era of globalization challenges the provision of safe healthcare and integrity to the supply chain in addressing all forms of hazardous, illegal and counterfeit drugs a drug that seriously endangers patient safety and public health [15-17]. This is influenced by insufficient funding, inability to predict accurately, lack of initiatives to maintain stocks, inefficient distribution systems $[11,18]$ and theft of drugs for resale to the private sector [11,19] the process of counterfeiting drugs [16, 17].

Pharmaceutical companies or industries must acquire new resources used to promote continuous innovation of the development process [20] in reducing risk and uncertainty in terms of time recovery, quantity, quality, estimation of production processes, and all in the resolution of a decision [19, 21]. Grossmann discloses that product discovery and development, design, supply chain simplification and life cycle make the main challenge in the pharmaceutical industry. Bhakoo and Chan [22] disclose more complex pharmaceutical supply chains than other industries. It requires good participation from various interested parties such as pharmaceutical manufacturers, wholesalers, distributors, customers, information service providers, and regulatory bodies $[19,21]$.

With So Complex, this sector is very less researched by researchers because it is considered not to contribute significantly in all markets, especially in developing countries. Interestingly observed by Varun [23] it turns out that the existing pharmaceutical industry has produced generic drugs that have low cost available in the domestic market. With the things described in the previous research, researchers found a gap that occurred in the literature that has been done in the past. This is what makes researchers interested to describe the key issues that occur in the development of the pharmaceutical industry.

\section{STRATEGIC ISSUES IN PHARMACEUTICAL SUPPLY CHAINS}

The challenges facing the entire pharmaceutical organization include improvements in service delivery, health care reform, patent values, and global drug quality standards. The activities of the pharmaceutical supply chain should be able to provide quality medicines according to WHO standards [13], quantity on-demand and timely distribution. Where everything has to face the challenge of reducing production costs, increasing the speed of the market. Therefore, the global strategic planning of the market becomes successful and easy. Shah and souse [1,7] raised essential issues when designing and developing pharmaceutical supply chains, such as network design, plant design, process development management and pipeline development and capacity planning.

The development of strategies and the optimization of support systems for decision making in product management is necessary to reduce risk, market time, optimize the objectives to accommodate the levels of greatest complexity [24, 25] the strategic aspects in the analysis of the competitiveness of the supply chain of the pharmaceutical industry can be exploited in Asset 25, processes and performance [26], people or interested persons [27-29] and technology [30] to improve the performance of the management of the supply chain. The researchers develop strategies for managing the supply chain with an important component that can be seen in Figure 1.

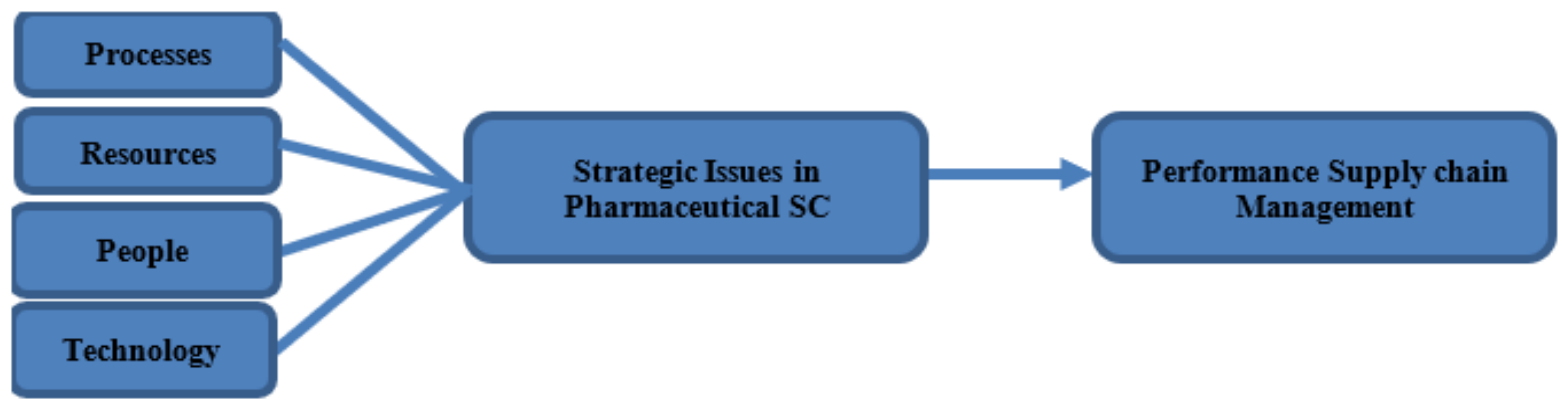

Figure 1. Research framework

\section{RESEARCH METHODOLOGY}

The approach used in this research is a systematic literature review (SLR). SLR is used as a way to identify, evaluate and interpret all existing research relevant to a topic [31]. With this SLR approach, researchers can focus more on solving existing problems. There is also a SLR step that is described as follows: 


\subsection{Search process}

The first step in the SLR method, finding and knowing the literature sources used are consistent, relevant and leading to the research being undertaken. The search is done on a pearl database and is widely used as a research reference. The journal database is used as follows:

- ACM Digital Library (dl.acm.org)

- IEEE Xplore Digital Library (http:/ieeexplore.ieee.org)

- JStor (www.jstor.com)

- Science Direct (www.sciencedirect.com)

- Emerald Insight (www.emeraldinsight.com)

- Taylor and Francis (tandfonline.com)

- US National Library of Medicine

In searching, a search keyword is used by using a Boolean operator. The use of Boolean operators aims to refine further the articles used. The composition of AND and OR operators used in keywords, among others:

- ('key issue AND 'supply 'AND ‘chain) OR ('pharmaceutical industry')

- ('pharmaceutical industry’ AND ‘supply 'AND ‘chain’ AND ‘key issue’)

- ('pharmaceutical industry' AND supply 'AND ‘chain)

- ('supply 'AND ‘chain AND 'Management' AND 'pharmaceutical industry')

\subsection{Inclusion criteria and extraction}

Inclusion criteria have three processes done, among others the first 'founded study' is an article discovery step that is in the database related keywords, the second "Study Candidate" is an article filter based on abstracts and titles relevant to the research, and the last "Selected Study "is an article filtering by reading the entire article that is relevant or appropriate to the research. The extraction process is done by finding 249 articles based on keywords and search databases. From the search process, it is extracted at the candidate stage found 137 articles, then do the selection of articles become selected articles found 57 articles to used research. Search process until extraction in April 2018 which can be seen in Table 1.

Table 1. Extraction studies in selected sources

\begin{tabular}{|c|c|c|c|}
\hline Source & Founded Studies & Candidate studies & Selected studies \\
\hline $\mathrm{ACM}$ & 18 & 5 & 1 \\
\hline Emerald insight & 60 & 30 & 12 \\
\hline IEEE & 22 & 12 & 2 \\
\hline JSTOR & 12 & 8 & 2 \\
\hline ScienceDirect & 80 & 50 & 29 \\
\hline TandF & 8 & 5 & 1 \\
\hline US National Library of Medicine & 19 & 10 & 4 \\
\hline Wiley & 22 & 12 & 4 \\
\hline Other & 8 & 5 & 2 \\
\hline Total & 249 & 137 & 57 \\
\hline
\end{tabular}

\section{RESULTS AND DISCUSSIONS}

\subsection{Publishing outlets}

The search process is done from various databases can we see the source of the article. The results are there 51 articles coming from journals, 4 articles come from conferences, and 2 articles from others. Everything can be seen in the following Table 2.

Table 2. Source of publishing outlets

\begin{tabular}{ccc}
\hline Journal/conference & $\#$ & $\%$ \\
\hline Conference & 4 & 7.0 \\
Journal & 51 & 89.5 \\
other & 2 & 3.5 \\
\hline
\end{tabular}

\subsection{Author according to country}

The development of supply chain research illustrates that several countries have been involved. According to the search results of US researchers The United States, India, the United Kingdom, Italy, 
Turkey, and China are the leading countries. In this study, it is reviewed by considering the various countries that can be seen in Figure 2 so that it has variations of research available in various countries.

\section{Author according to country}

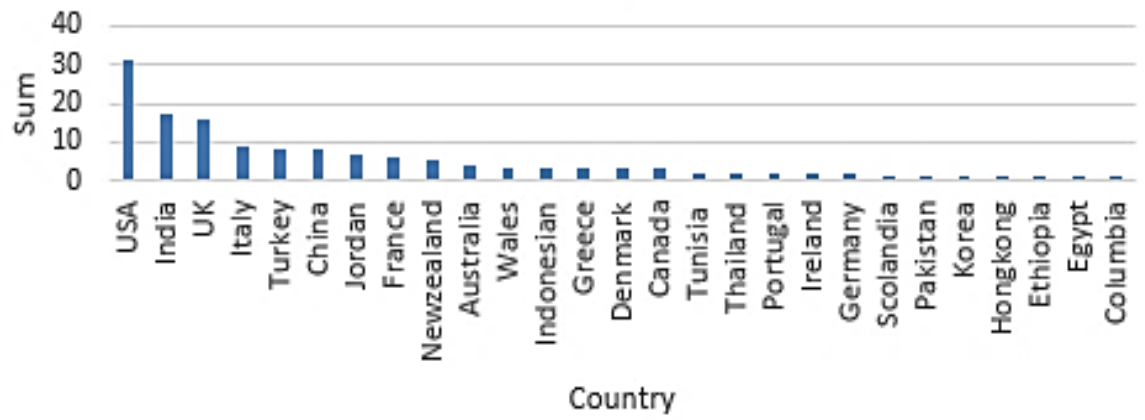

Figure 2. Author according to country

\subsection{Mapping research issues, and references}

The review was conducted in search of key issues in the pharmaceutical supply chain based on 57 articles that fit the topic of this study so that it was analyzed and used to create the main strategic framework shown in Figure 1. The issues found can be seen in Table 3. All issues grouped into resources, processes, people, information technology, performance.

Table 3. Summary of research issues

\begin{tabular}{llc}
\hline \multicolumn{1}{c}{ Research Issues } & \multicolumn{1}{c}{ References } & Total \\
\hline Strategy development Concepts & {$[1,7,13,24-30]$} & 10 \\
Resources of Pharmaceutical SC & & \\
New product development capabilities & {$[32-35]$} & 4 \\
New process development & {$[11,25,36]$} & 3 \\
Capacity planning & {$[1,37]$} & 2 \\
Plant \& Network design & {$[38-42]$} & 5 \\
Pipeline and development management & {$[43,44]$} & 2 \\
e-business capabilities & {$[25,45,46]$} & 3 \\
People & {$[28,47,48]$} & 3 \\
Information Technology & {$[47,49-52]$} & 5 \\
Processes of Pharmaceutical SC & & \\
Outsourcing logistics activities & {$[4,53-56]$} & 5 \\
Inventory management & {$[10,57-63]$} & 9 \\
Reverse logistics & {$[5,64,65]$} & 3 \\
Lean manufacturing & {$[66-71]$} & 7 \\
Quality Management & {$[40,49,72-74]$} & 4 \\
Performance issues in Pharmaceutical SC & {$[75-82]$} & 8 \\
Total & & 73 \\
\hline
\end{tabular}

\subsection{Mapping research issue of pharmaceutical supply chain}

\subsubsection{Resource of pharmaceutical supply chain}

The organization or company must have a resource asset. The resources that are used effectively and efficiently in development and management will play a very important role in competition in the supply chain. The resources consist of:

- New product development capabilities (NPD)

The application of NPD to pharmaceutical companies is used to increase the competition for business strategies that are so fast and advanced [35]. Factors that can be NPD development include rapid technological advances, higher costs, shorter product life cycles [33]. NPD itself will use resources very much to be provided by the company, then it raises the problem, especially long development time, low success rate, high capital requirement, and market uncertainty [32]. The NPD of the pharmaceutical industry should compare and adopt the workings of other industries to be more effective and efficient $[34,35]$.

Key strategic issues pharmaceutical industry of SCM: A systematic literature review (Erick Fernando) 
- New process development capability

The new process development capability strategy is a must in the continuity of new drug development in the pharmaceutical industry [36]. The development process is very important because any field involves a cycle process, beginning with an exploratory study using interviews/surveys, followed by case studies and theoretical formulations [11]. Efficient and optimized development can provide good performance, increase productivity, help reduce production costs, improve the achievement of better product inventions, and develop production processes and design [25]. The development process is done by testing phases of drugs, construction, and commercial design forms [25].

- Capacity planning

Capacity planning involves everything employed within the supply chain, all through the uncertainty of clinical testing [37]. It has been observed by [1] that capacity planning at great risk, this is a product failure during trials, product withdrawal that is considered to be unsuccessful during sale due to side effects, uncertainty about drug dosage and composition, competition from similar products, demand requirements the drug is uncertain. Thus, effective capacity planning and utilization is a major challenge for the pharmaceutical sector.

- Plant and network design

Design planning activities are an important element in improving performance probabilities in the supply chain [38, 39]. Arshinder [39] says that the trend occurs in the production and distribution of the supply chain to the people who need it. This is traced to all supply chain activities involving wholesale manufacturers, and distributors until the patient is a necessary approach that can reduce operating costs [38, 39]. The design of an integrated systematic supply chain can enhance highly optimized coordination [39, 40]. The importance of timely product distribution in the drug industry leads to network optimization due to variations in infrastructure and lack of connectivity [40, 42]. Researchers should explore the optimal network under dynamic operational conditions with different reference regions.

- Improvement in research \& development capabilities

The pharmaceutical industry in R \& D development is used to create new innovations to compete with other companies. R \& D urgently requires significant and numerous resources [43]. In many pharmaceutical industries in several countries using $\mathrm{R} \& \mathrm{D}$ joint ventures, mergers, and outsourcing various phases of pharmaceutical $\mathrm{R} \& \mathrm{D}$ activities for faster and cost-effective methods of innovation. This development requires an optimal managerial to know, evaluate the current movement in the market, formulate successful models, and create competitive strategies to take preemptive action in a rapidly changing global environment. Thus, companies will achieve efficient innovation as they focus on developing a high level of strategic cognition and managerial openness [43, 44]. Therefore, this factor is crucial in offering an internal locus view of innovation that the pharmaceutical R \& D needs to produce efficiently.

- Pipeline and development management

In the development process occurring within the pharmaceutical industry must be done by pipeline as it helps in scheduling the problem effectively [25]. This process involves the selection of potential drugs for further development $[45,46]$. In this approach, each product has a specific set of tests and is characterized by duration, cost, priority limits, resource requirements, and the probability of success [45, 83]. Scheduling a variety of cross-pipe testing under dynamic market requirements is a challenging task.

- E-business capabilities

E-business is a form of a business model that changes from traditional to more innovative ways that use the internet in helping process models [53-55]. Croom [56] also mentions e-business systems and processes that use a web browser and internet platforms have a major impact on inter-organizational process management. The ability of e-business affects in increasing supply chain processes that occur within the company [53]. The use of e-business is used to reduce transaction costs by using demand, improving operational efficiency, enabling organizations to gain access to expansion from the entire supply chain [4].

\subsubsection{Processes of pharmaceutical supply chain}

Processes in the pharmaceutical industry include the scheduling of all process activities in the supply chain. The planning process should be more effective and efficient to improve the responsiveness and speed of the supply chain. The process will be discussed below:

- Outsourcing logistics activities

In the development of the world of logistics, lately, it has been known as outsourcing. Outsourcing is an action to move some of the company's internal activities and assign decision responsibilities to third parties [84]. Pharmaceutical companies currently also deliver logistical activities to third parties (3PLs) [84]. Outsourcing logistics is undergoing a rapid development that was once only feared in the warehousing and transportation sections, and now they can provide services in a variety of circumstances [85]. 
Thus, outsourcing provides advantages in costing costs to help accelerate the process of innovation that occurs within the pharmaceutical industry [86]. Monica [87] reveals the main reasons for outsourcing: financial savings, an increased ability to focus on strategic issues, access to technology and specialized expertise, and an ability to demand measurable and improved service levels. In addition, in the application of outsourcing can provide risk in the pharmaceutical industry

- Reverse logistics

The management of waste management returns in terms of waste minimization, reuse or recycling of materials has become a concern in national and international regulations [64]. This is particularly important in relation to how the drug process that is no longer feasible for the use of examples due to exposure to the drug can be sent to the manufacturer [5]. In observations made by Xie [5], the logistics provider has a role in the process of collecting pharmaceutical waste from several pharmacies and delivers it to the factory. This process should involve logistics providers and wholesalers to collect, sort, recycle and discard, or cooperate with other actors in the system [5]. Biel [65] observes that the work processes of the supply chain will be more complex and richer in the face of high uncertainty, can affect the collection rate, the availability of recycled production inputs and the capacity of the network is reversed. Designing an upside-down logistics network is a costly and challenging task for the pharmaceutical sector due to the high level of uncertainty in the supply chain. The researchers will explore the problem of reverse logistics optimization for the pharmaceutical sector. Therefore, researchers can explore the problem of reverse logistics optimization for the pharmaceutical sector.

- Inventory management

In the pharmaceutical industry, pharmaceutical management has been particularly important to meet customer demand, especially hospitals that transport large quantities and various medications for emergency needs [57-59]. Pharmaceutical products provide a special burden and have an additional risk of loss of product value $[60,61]$ since the products are made of synthesized organic compounds or contain active and sensitive molecular entities that may diminish over time even with superior packaging and careful control against environmental conditions [10]. This is reinforced by the findings of Jan Devries in a number of pharmaceutical organizations or companies that have implemented good inventory management to reduce costs and improve customer service [60-63]. With such complexity, researchers can explore more about the problems or models that can be used in the pharmaceutical industry to reduce supply chain risks associated with product types, product lifecycle and product delivery time.

- Lean manufacturing

In modern manufacturing, the implementation of lean manufacturing principles is a vital requirement to compete globally, with the objective of minimizing waste and maximizing the production flow based on Toyota system production (TPS) [66, 67]. TPS has divided 7 residues that Palin's base in the world of the industry is the product's identity, purity, potency, uniformity of dosage form, bioavailability, and increased public awareness about counterfeit medicines [88]. In his research, Rahman [68] said that the disciplined, consistent and correct use of lean manufacturing can reduce even the elimination of waste and streamline processes in order to provide business excellence. In the application of good manufacturing and integrated together you can create communication in a faster and cleaner environment so you can simplify the process of product flow that impacts on time and cost reduction [68-72]. In the pharmaceutical industry in Indonesia, it is seen that it is still new in the implementation of lean manufacturing. Researchers can conduct studies to improve tight manufacturing in the pharmaceutical sector and its impact on operational performance.

- Quality management

In the pharmaceutical quality of the drug must meet the standards that have been determined. The standard has been determined by the WHO, which defined "products whose compositions and ingredients do not meet the true scientific specifications and which, consequently, are ineffective" [73]. Greene and O'Rourke [73, 74] said that true quality standards and discipline within the pharmaceutical industry focus on safety and quality manufacturing processes in accordance with applicable standards. In addition to Patel [40], he emphasizes that the application of the quality of drug distribution in the pharmaceutical industry can reduce the risk of inferior and even false quality medicines. Newton [74] also reveals the effective regulation of medicines as a challenging task due to the limited availability of resources in developing countries, so he faces many challenges in the context of quality problems. Therefore, the researcher should suggest a strategic framework to address such quality problems.

\subsubsection{Information Technology of pharmaceutical supply chain}

The use of information technology within SCM is imperative for companies to compete well in the current era [49-51]. The use of IT can provide a complete exchange of information between supply chain activities and can connect internal and external business functions of the industry [51, 89] so that

Key strategic issues pharmaceutical industry of SCM: A systematic literature review (Erick Fernando) 
the industry can improve efficiency, productivity, and profitability [47, 50, 52]. Researchers can explore further the influence of IT in this SCM.

\subsubsection{People of the pharmaceutical supply chain}

SCM are all activities related to the design, planning, synthesis, organization and control of the supply chain. SCM's research activities are evolving, with efforts tailored to innovation to reduce the pressure that culminates in the supply chain. People are a key factor in the implementation of all activities in the supply chain [90]. Psychological factors as behavioral antecedents [48], researchers should explore the exploration of the factors that affect people in order to carry out local activities as well.

\subsubsection{Performance management of pharmaceutical supply}

The performance management of the pharmaceutical industry depends to a large extent on the resources and processes that occur in the supply chain. In the pharmaceutical industry, the increase in research and development $(\mathrm{R} \& \mathrm{D})$ costs, the life cycle of the product is reduced and the awareness of fast-growing suppliers and consumers. This changes the standard of performance management with the daily process. By implementing SCM in the pharmaceutical industry, in fact, it wants to improve the most competitive performance that is done through close integration with the function of the internal company [75]. Therefore, this performance can be effectively linked to each other (providers, customers, and other channel members) [76-78].

Supply chain capabilities developed with high-level integration on the supply side and demand capabilities of manufacturers can improve product quality and delivery reliability capabilities, thus providing sales growth [79, 80]. Dangayach [81] has observed that companies that can manage their practical resources in the supply chain more efficiently tend to gain competitive capacity. It can be concluded that the pharmaceutical industry to improve performance and the management of its resources and market share is influenced by flexibility, quality, and cost, which in general cannot be separated from any investment, advisory or market action [82]. To improve overall performance, organizations must work in all social, environmental and economic areas. For this, they need to integrate their resources and processes with performance measures. These factors can be considered by researchers in the development of frameworks and validation by empirical studies or case studies.

\section{CONCLUSION}

The implementation of supply chain management in this global era, which makes the industry more competitive. However, in the last decade, several pharmaceutical development companies are one that has a very complex supply chain. The decision to implement the supply chain is very important, such as those related to the acquisition or introduction of new products, the operations of the process, as well as the organizations that play a role in the discovery, development and manufacture of medicines which may be more useful in human life. The use of these drugs does not escape the function of all the processes that exist within the pharmaceutical industry, and therefore requires the supply chain. The supply chain is special to the others, where the process is carried out manufacturing drugs, delivery, and to be consumed by the customer. With that, the importance of the supply chain management approach makes the company succeed in the competition. The results of the searches conducted found the problem - an important issue in the pharmaceutical industry, among others: product and process development, capacity planning, plant design and networking, e-commerce and IT, management inventory, outsourcing and logistics upside down, the problem of the lean supply chain and green measures of performance, people and information technology. These searches also find USA, India, United Kingdom, Italy, Turkey, China is a country-a leader in the development of the supply chain. The problem is a strategic problem that improves the performance of the management of the supply chain in the pharmaceutical industry.

\section{REFERENCES}

[1] N. Shah, "Pharmaceutical supply chains: Key issues and strategies for optimisation," Comput. Chem. Eng., vol. 28, no. 6-7, pp. 929-941, 2004.

[2] E. Fernando, Surjandy, H. L. H. S. Warnars, Meyliana, R. Kosala, and E. Abdurachman, "Critical success factor of information technology implementation in supply chain management: literature review," Proc.-2018 5th Int. Conf. Inf. Technol. Comput. Electr. Eng. ICITACEE 2018, pp. 315-319, 2018.

[3] J. F. Shapiro, "Challenges of strategic supply chain planning and modeling," Comput. Chem. Eng., vol. 28, no. 6-7, pp. 855-861, 2004.

[4] R. K. Singh, R. Kumar, and P. Kumar, "Strategic issues in pharmaceutical supply chains: a review," Int. J. Pharm. Healthc. Mark., vol. 10, no. 3, pp. 234-257, 2016. 
[5] Y. Xie and L. Breen, "Greening community pharmaceutical supply chain in UK: a cross boundary approach," Supply Chain Manag. An Int. J., vol. 17, no. 1, pp. 40-53, 2012.

[6] L. G. Papageorgiou, "Supply chain optimisation for the process industries: Advances and opportunities," Comput. Chem. Eng., vol. 33, no. 12, pp. 1931-1938, 2009.

[7] R. R. T. Sousa, N. Shah, and L. L. G. Papageorgiou, "Global supply chain network optimisation for pharmaceuticals," Computer Aided Chemical Engineering, vol. 20, pp. 1189-1194, 2005.

[8] L. Papageorgiou, G. Rotstein, and N. Shah, "Strategic supply chain optimization for the pharmaceutical industries," Ind. Eng. Chem. Res., vol. 40, no. 1, pp. 275-286, 2001.

[9] H. L. H. L. Lee, "Aligning supply chain strategies with product uncertainties," Calif. Manage. Rev., vol. 44, no. 3, pp. 105-119, 2002.

[10] J. M. Laínez, E. Schaefer, and G. V. Reklaitis, "Challenges and opportunities in enterprise-wide optimization in the pharmaceutical industry," Comput. Chem. Eng., vol. 47, pp. 19-28, 2012.

[11] S. A. Narayana, R. K. Pati, and P. Vrat, "Research on management issues in the pharmaceutical industry: a literature review," Int. J. Pharm. Healthc. Mark., vol. 6, no. 4, pp. 351-375, 2012.

[12] M. A. Talias, "Optimal decision indices for R\&D project evaluation in the pharmaceutical industry: Pearson index versus Gittins index,” Eur. J. Oper. Res., vol. 177, no. 2, pp. 1105-1112, 2006.

[13] World Health Organization, World Health Statistics 2017 : Monitoring Health for The SDGs. 2017.

[14] B. S. Behera, B. Panda, R. A. Behera, N. Nayak, A. C. Behera, and S. Jena, "Information communication technology promoting retail marketing in agriculture sector in India as a study," Procedia Comput. Sci., vol. 48, pp. 652-659, 2015.

[15] Tim K Mackey and Bryan A Liang, "Improving global health governance to combat counterfeit medicines: A proposal for a UNODC-WHO-Interpol trilateral mechanism," BMC Med,. pp. 1-10, 2016.

[16] B. A. Liang, "Fade to black: Importation and counterfeit drugs," Am. J. Law Med., vol. 32, no. 2-3, pp. 279-323, 2006.

[17] B. A. Liang, T. Kubic, T. K. Mackey, and P. York, "Counterfeit drug penetration into global legitimate medicine supply chains: A global assessment,” Am. J. Trop. Med. Hyg., vol. 92, no. 6_Suppl, pp. 59-67, 2015.

[18] R. Kaynak, İ. Koçoğlu, and A. E. Akgün, "The role of reverse logistics in the concept of logistics centers," Procedia-Soc. Behav. Sci., vol. 109, pp. 438-442, 2014.

[19] S. K. Srivastava, "Network design for reverse logistics," Omega, vol. 36, no. 4, pp. 535-548, 2008.

[20] B. Ageron, O. Lavastre, and A. Spalanzani, "Innovative supply chain practices: the state of French companies," Supply Chain Manag. An Int. J., vol. 18, no. 3, pp. 265-276, 2013.

[21] K. S. Sangwan, "Key activities, decision variables and performance indicators of reverse logistics," Procedia CIRP, vol. 61, pp. 257-262, 2017.

[22] V. Bhakoo and C. Chan, "Collaborative implementation of e-business processes within the health-care supply chain: The Monash pharmacy project," Supply Chain Manag. An Int. J., vol. 16, no. 3, pp. 184-193, 2011.

[23] F. Zarenezhada, G. Mehralianb, and A. RajabzadehGhataric, "Developing a model for agile pharmaceutical distribution: Evidence from Iran," J Basic Appl Sci Res, vol. 3, no. 1, pp. 161-172, 2013.

[24] X. Wan, J. F. Pekny, and G. V Reklaitis, "Simulation based optimization for risk management in multi-stage capacity expansion," Syst. Eng., no. 1, pp. 1881-1886, 2006.

[25] J. L. Perez-Escobedo, C. Azzaro-Pantel, and L. Pibouleau, "Multiobjective strategies for new product development in the pharmaceutical industry," Comput. Chem. Eng., vol. 37, pp. 278-296, 2012.

[26] R. K. Singh and M. K. Sharma, "Selecting competitive supply chain using fuzzy AHP and extent analysis," J. Ind. Prod. Eng., vol. 31, no. 8, pp. 524-538, 2014.

[27] M. L. Lengnick-hall, C. A. Lengnick-hall, and C. M. Rigsbee, "Human Resource Management Review Strategic human resource management and supply chain orientation," Hum. Resour. Manag. Rev., pp. 1-12, 2012.

[28] M. Kasonde and P. Steele, "The people factor: An analysis of the human resources landscape for immunization supply chain management q," Vaccine, vol. 35, no. 17, pp. 2134-2140, 2017.

[29] A. Brown, M. Atif, E. Hasselberg, P. Steele, C. Wright, and Z. Babar, "Human resources health supply chains and access to essential medicines," J. Pharm. Policy Pract., vol. 7, no. Suppl 1, pp. 1-2, 2015.

[30] M.-L. Tseng, K.-J. Wu, and T. T. Nguyen, "Information technology in supply chain management: a case study," Procedia-Soc. Behav. Sci., vol. 25, no. 2010, pp. 257-272, 2011.

[31] B. Kitchenham, O. P. Brereton, D. Budgen, M. Turner, J. Bailey, and S. Linkman, "Systematic literature reviews in software engineering-A systematic literature review," Inf. Softw. Technol., vol. 51, no. 1, pp. 7-15, 2009.

[32] N. Yousefi, G. Mehralian, H. R. Rasekh, and M. Yousefi, "New Product Development in the Pharmaceutical Industry: Evidence from a generic market.," Iran. J. Pharm. Res. IJPR, vol. 16, no. 2, pp. 834-846, 2017.

[33] A. K. Gupta and D. L. Wilemon, "Accelerating the Development of Technology-Based New Products," Calif. Manage. Rev., vol. 32, no. 2, pp. 24-44, Jan. 1990.

[34] E. Mazzola, M. Bruccoleri, and G. Perrone, "Supply chain of innovation and new product development," J. Purch. Supply Manag., vol. 21, no. 4, pp. 273-284, 2015.

[35] V. Chiesa and G. Toletti, "Network of collaborations for innovation: The case of biotechnology," Technol. Anal. Strateg. Manag., vol. 16, no. 1, pp. 73-96, Mar. 2004.

[36] J. Baker, A. Parasuraman, D. Grewal, and G. B. Voss, "The Influence of multiple store environment cues on perceived merchandise value and patronage intentions," J. Mark., vol. 66, no. 2, pp. 120-141, Apr. 2002.

[37] G. Gatica, L. G. Papageorgiou, and N. Shah, "Capacity planning under uncertainty for the pharmaceutical industry," Chem. Eng. Res. Des., vol. 81, no. 6, pp. 665-678, 2003.

[38] A. Drira, H. Pierreval, and S. Hajri-Gabouj, "Facility layout problems: A literature analysis," IFAC Proc. Vol.,

Key strategic issues pharmaceutical industry of SCM: A systematic literature review (Erick Fernando) 
vol. 12, part 1, 2006.

[39] Arshinder, A. Kanda, and S. G. Deshmukh, "Supply chain coordination: Perspectives, empirical studies and research directions," Int. J. Prod. Econ., vol. 115, no. 2, pp. 316-335, 2008.

[40] A. Patel, P. Norris, R. Gauld, and T. Rades, "Drug quality in South Africa: Perceptions of key players involved in medicines distribution," Int. J. Health Care Qual. Assur., vol. 22, no. 5, pp. 547-560, 2009.

[41] R. D. Mesbah, A., Lakerveld, R., Braatz, "Plant-wide model predictive control of a continuous pharmaceutical manufacturing process," Present. 2013 AIChE Annu. Meet. San Fr. CA, pp. 1-2, 2013.

[42] I. Grossmann, "Enterprise-wide optimization: A new frontier in process systems engineering," AIChE J., vol. 51, no. 7, pp. 1846-1857, 2005.

[43] C. Liu, P. P. Constantinides, and Y. Li, "Research and development in drug innovation: reflections from the 2013 bioeconomy conference in China, lessons learned and future perspectives," Acta Pharm. Sin. B, vol. 4, no. 2, pp. 112-119, 2014.

[44] G. Hollinshead, "The tortuous ascent of global value chains-the case of pharmaceutical R\&amp;D in China," Crit. Perspect. Int. Bus., vol. 13, no. 3, pp. 244-262, 2017.

[45] E. Brandon-Jones, B. Squire, C. W. Autry, and K. J. Petersen, "A contingent resource-based perspective of supply chain resilience," J. Supply Chain Manag., vol. 50, no. 3, pp. 55-73, 2014.

[46] E. Hassini, C. Surti, and C. Searcy, "A literature review and a case study of sustainable supply chains with a focus on metrics," Int. J. Prod. Econ., vol. 140, no. 1, pp. 69-82, 2012.

[47] J. H. Han, Y. Wang, and M. Naim, "Reconceptualization of information technology flexibility for supply chain management: An empirical study,” Int. J. Prod. Econ., vol. 187, pp. 196-215, 2017.

[48] T. Schorsch, C. M. Wallenburg, and A. Wieland, "The human factor in SCM," Int. J. Phys. Distrib. Logist. Manag., vol. 47 , no. 4 , pp. 238-262, 2017.

[49] E. W. T. Ngai, D. C. K. Chau, and T. L. A. Chan, "Information technology, operational, and management competencies for supply chain agility: Findings from case studies," J. Strateg. Inf. Syst., vol. 20, no. 3, pp. 232-249, 2011.

[50] R. Narasimhan and S. W. Kim, "Information system utilization strategy for supply chain integration," J. Bus. Logist., vol. 22, no. 2, pp. 51-75, 2001.

[51] A. Gunasekaran, N. Subramanian, and T. Papadopoulos, "Information technology for competitive advantage within logistics and supply chains: A review," Transp. Res. Part E Logist. Transp. Rev., vol. 99, pp. 14-33, 2017.

[52] C. Marinagi, P. Trivellas, and D. P. Sakas, "The impact of information technology on the development of supply chain competitive advantage," Procedia - Soc. Behav. Sci., vol. 147, pp. 586-591, 2014.

[53] M. Chi, J. Zhao, Z. Lu, and Z. Liu, "Analysis of e-business capabilities and performance: From e-SCM process view," Proc.-2010 3rd IEEE Int. Conf. Comput. Sci. Inf. Technol. ICCSIT 2010, vol. 1, pp. 18-22, 2010.

[54] M. E. Johnson and S. J. Whang, "E-business and Supply chain management: An overview and framework," Prod. Oper. Manag., vol. 11, no. 4, pp. 413-423, 2002.

[55] Q. Tang and J. Huang, "Impact of web site functions on e-business success in chinese wholesale and retail industries," Tsinghua Sci. Technol., vol. 13, no. 3, pp. 368-373, 2008.

[56] S. R. Croom, "The impact of e-business on supply chain management," Int. J. Oper. Prod. Manag., vol. 25, no. 1, pp. 55-73, 2005.

[57] B. Balcik, C. D. C. Bozkir, and O. E. Kundakcioglu, "A literature review on inventory management in humanitarian supply chains," Surv. Oper. Res. Manag. Sci., vol. 21, no. 2, pp. 101-116, 2016.

[58] L. Nicholson, A. J. Vakharia, and S. Selcuk Erenguc, "Outsourcing inventory management decisions in healthcare: Models and application," Eur. J. Oper. Res., vol. 154, no. 1, pp. 271-290, 2004.

[59] D. Singh and A. Verma, "Inventory management in supply chain," Mater. Today Proc., vol. 5, no. 2, pp. 3867-3872, 2018.

[60] S. Mitra, "Inventory management in a two-echelon closed-loop supply chain with correlated demands and returns," Comput. Ind. Eng., vol. 62, no. 4, pp. 870-879, 2012.

[61] A. M. Atieh et al., "Performance improvement of inventory management system processes by an automated warehouse management system," Procedia CIRP, vol. 41, pp. 568-572, 2016.

[62] A. D. Guritno, R. Fujianti, and D. Kusumasari, "Assessment of the supply chain factors and classification of inventory management in suppliers' level of fresh vegetables," Agric. Agric. Sci. Procedia, vol. 3, pp. 51-55, 2015.

[63] F. Costantino, G. Di Gravio, A. Shaban, and M. Tronci, "The impact of information sharing and inventory control coordination on supply chain performances," Comput. Ind. Eng., vol. 76, pp. 292-306, 2014.

[64] S. S. Kara and S. Onut, "A two-stage stochastic and robust programming approach to strategic planning of a reverse supply network: The case of paper recycling," Expert Syst. Appl., vol. 37, no. 9, pp. 6129-6137, 2010.

[65] S. K. Srivastava and R. K. Srivastava, "Managing product returns for reverse logistics," Int. J. Phys. Distrib. Logist. Manag., vol. 36, no. 7, pp. 524-546, 2006.

[66] D. T. Matt, “Template based production system design,” J. Manuf. Technol. Manag., vol. 19, no. 7, pp. 783-797, 2008.

[67] S. Vinodh, K. R. Arvind, and M. Somanaathan, "Application of value stream mapping in an Indian camshaft manufacturing organisation,” J. Manuf. Technol. Manag., vol. 21, no. 7, pp. 888-900, 2010.

[68] S. Rahman, T. Laosirihongthong, and A. S. Sohal, "Impact of lean strategy on operational performance: A study of Thai manufacturing companies," J. Manuf. Technol. Manag., vol. 21, no. 7, pp. 839-852, 2010.

[69] T. Melton, "The benefits of lean manufacturing: What lean thinking has to offer the process industries," Chem. Eng. Res. Des., vol. 83, no. 6 A, pp. 662-673, 2005. 
[70] H. Afonso and M. D. R. Cabrita, "Developing a lean supply chain performance framework in a SME: A perspective based on the balanced scorecard," Procedia Eng., vol. 131, pp. 270-279, 2015.

[71] A. Fercoq, S. Lamouri, V. Carbone, A. Lelièvre, and A. A. Lemieux, "Combining lean and green in manufacturing: A model of waste management," IFAC Proceedings Volumes, vol. 46, no. 9, 2013.

[72] World Health Organization, "Annex 5 WHO good distribution practices for pharmaceutical products," WHO Tech. Rep. Ser., no. 957, pp. 235-264, 2010.

[73] Dermot O'Rourke, Anne Greene, "Lean Manufacturing practice in a cGMP environment," Pharmaceutical Technology Europe, vol. 18, no. 10, 2006.

[74] P. N. Newton, M. D. Green, F. M. Fernández, N. P. Day, and N. J. White, "Counterfeit anti-infective drugs," Lancet Infect. Dis., vol. 6, no. 9, pp. 602-613, 2006.

[75] S. W. Kim, "An investigation on the direct and indirect effect of supply chain integration on firm performance," Int. J. Prod. Econ., vol. 119, no. 2, pp. 328-346, 2009.

[76] N. R. Sanders and R. Premus, "Modeling the relationship between firm it capability, collaboration, and performance," J. Bus. Logist., vol. 26, no. 1, pp. 1-23, 2005.

[77] X. Koufteros, M. Vonderembse, and J. Jayaram, "Internal and external integration for product development: The contingency effects of uncertainty, equivocality, and platform strategy,” Decis. Sci., vol. 36, no. 1, pp. 97-133, 2005.

[78] S. Vachon and R. D. Klassen, "Environmental management and manufacturing performance: The role of collaboration in the supply chain," Int. J. Prod. Econ., vol. 111, no. 2, pp. 299-315, 2008.

[79] R. Edward A. M., "Supply chain strategies, capabilities, and performance," Transp. J., vol. 41, no. 1, pp. 37-54, 2016.

[80] E. D. Rosenzweig, A. V. Roth, and J. W. Dean, "The influence of an integration strategy on competitive capabilities and business performance: An exploratory study of consumer products manufacturers," J. Oper. Manag., vol. 21, no. 4, pp. 437-456, 2003.

[81] G. S. Dangayach and S. G. Deshmukh, "Manufacturing strategy: Literature review and some issues," Int. J. Oper. Prod. Manag., vol. 21, no. 7, pp. 884-932, 2001.

[82] C. Zehir, Ö. G. Ertosun, S. Zehir, and B. Müceldilli, “Total Quality Management Practices' Effects on Quality Performance and Innovative Performance," Procedia-Soc. Behav. Sci., vol. 41, pp. 273-280, 2012.

[83] Y. Boulaksil and J. C. Fransoo, "Implications of outsourcing on operations planning: findings from the pharmaceutical industry," Int. J. Oper. Prod. Manag., vol. 30, no. 10, pp. 1059-1079, 2010.

[84] E. Aktas, B. Agaran, F. Ulengin, and S. Onsel, "The use of outsourcing logistics activities: The case of turkey," Transp. Res. Part C, vol. 19, no. 5, pp. 833-852, 2011.

[85] L. E. Gadde and K. Hulthén, "Improving logistics outsourcing through increasing buyer-provider interaction," Ind. Mark. Manag., vol. 38, no. 6, pp. 633-640, 2009.

[86] M. Graf and S. M. Mudambi, "The outsourcing of IT-enabled business processes: A conceptual model of the location decision," J. Int. Manag., vol. 11, no. 2 SPEC. ISS., pp. 253-268, 2005.

[87] M. Belcourt, "Outsourcing-The benefits and the risks," Hum. Resour. Manag. Rev., vol. 16, no. 2, pp. 269-279, 2006.

[88] S. Shingo, "Study of the Toyota Production System from an Industrial Engineering Viewpoint," book; Productivity Press, p. 257, 1989.

[89] A. Z. Acar and M. B. Uzunlar, "The effects of process development and information technology on time-based supply chain performance," Procedia-Soc. Behav. Sci., vol. 150, pp. 744-753, 2014.

[90] H. Pateman, K. Hughes, and S. Cahoon, "Humanizing humanitarian supply chains : A synthesis of key challenges," Asian J. Shipp. Logist., vol. 29, no. 1, pp. 81-102, 2013. 